\title{
NGF Is Essential for Hippocampal Plasticity and Learning
}

\author{
James M. Conner, ${ }^{1 \star}$ Kevin M. Franks, ${ }^{2,3 *}$ Andrea K. Titterness, ${ }^{6 \star}$ Kyle Russell, ${ }^{6}$ David A. Merrill, ${ }^{1}$ Brian R. Christie,${ }^{6,7}$ \\ Terrence J. Sejnowski, ${ }^{2,3,4}$ and Mark H. Tuszynski ${ }^{1,5}$ \\ Departments of ${ }^{1}$ Neurosciences and ${ }^{2}$ Biology, University of California, San Diego, La Jolla, California 92093, ${ }^{3}$ Computational Neurobiology Laboratory, \\ Salk Institute for Biological Studies, La Jolla, California 92037, ${ }^{4}$ Howard Hughes Medical Institute, ${ }^{5}$ Veterans Administration Medical Center, San Diego, \\ California 92161, ${ }^{6}$ Neuroscience Program, University of British Columbia, Vancouver, British Columbia V6T 1Z4, Canada, and ${ }^{7}$ Division of Medical \\ Sciences, University of Victoria, Victoria, British Columbia V8W 2Y2, Canada
}

Nerve growth factor (NGF) is produced in the hippocampus throughout life and is retrogradely trafficked to septal cholinergic neurons, providing a potential mechanism for modulating cholinergic inputs and, thereby, hippocampal plasticity. To explore NGF modulation of hippocampal plasticity and function, NGF levels were augmented or blocked in intact adult rats, and subsequent in vivo effects on cholinergic neurons, hippocampal long-term potentiation (LTP), and learning were examined. NGF augmentation significantly enhanced cholinergic neuronal markers and facilitated induction of hippocampal LTP. Blockade of endogenous NGF significantly reduced hippocampal LTP and impaired retention of spatial memory. These findings reveal an essential role for NGF in regulating biological mechanisms related to plasticity and memory in the intact adult brain.

\section{Introduction}

The actions of nerve growth factor (NGF) in reversing lesion- and age-related degeneration of basal forebrain cholinergic neurons in the adult CNS have been well defined (Conner and Tuszynski, 1999). However, the physiological role of NGF within the intact adult CNS remains unexplored for the most part. Existing evidence suggests that NGF could act as a dynamic modulator of basal forebrain cholinergic projections to the hippocampus: (1) NGF expression within basal forebrain targets, the hippocampus and neocortex, is maintained at high levels throughout life (Large et al., 1986; Whittemore et al., 1986), and withdrawal of NGF induces cholinergic neuronal atrophy (Sofroniew et al., 1990); (2) cholinergic neurons actively transport NGF retrogradely from these regions of production to their somata in the basal forebrain (Schwab et al., 1979), leading to active NGF turnover throughout adulthood (Conner and Varon, 1992; Brooks et al., 2000); and (3) cholinergic neurons of the basal forebrain are the only neuronal system in the brain to constitutively express both trkA and p75NTR (p75 neurotrophin) receptors (Sobreviela et al., 1994), suggesting a unique sensitivity to NGF on an ongoing basis.

Despite ample evidence indicating that NGF can modulate the functional state of cholinergic systems projecting to hippocampal and cortical targets, along with experimental demonstrations that acetylcholine can influence various aspects of synaptic plasticity,

\footnotetext{
Received May 29, 2009; revised July 21, 2009; accepted July 22, 2009.

This work was supported by National Institutes of Health Grants AG10435, NS37083, and AG05131, the Veterans Administration, the Alzheimer's Association, The Shiley Family Foundation, and Canadian Institutes of Health Research. We thank Andy Chen for performing ChAT assays and Lee Campbell for writing software used in electrophysiological analysis.

*J.M.C., K.M.F., and A.K.T. contributed equally to this work.

Correspondence should be addressed to Mark H. Tuszynski, Department of Neurosciences 0626, University of California, San Diego, La Jolla, CA 92093. E-mail: mtuszynski@ucsd.edu.

DOI:10.1523/JNEUROSCI.2594-09.2009

Copyright $\odot 2009$ Society for Neuroscience $\quad$ 0270-6474/09/2910883-07\$15.00/0
}

there has been no direct examination of the hypothesis that NGF availability influences hippocampal plasticity and function in the intact adult brain specifically by acting on cholinergic systems. To test this hypothesis, NGF availability, specifically within the septo-hippocampal system, was either augmented or blocked, and consequences of these manipulations on cholinergic neuronal morphology, hippocampal synaptic transmission, and spatial learning were determined. We now report distinct effects of NGF on cellular, electrophysiological, and behavioral plasticity in the intact adult CNS.

\section{Materials and Methods}

A total of 112 adult female F344 rats (175-200 g) were subjects of this study. Rats were 3-4 months of age when studies were initiated and were $<5$ months of age at the completion of the studies. Of these, 32 animals received NGF infusions, 18 received anti-NGF infusions, 11 received IgG 192-saporotoxin lesions, 45 received control (vehicle) infusions, and 6 were untreated (intact). All studies were performed under protocols approved by the institutional animal committee in accordance with international ethical care guidelines. Rats were housed in groups of three, were on a $12 \mathrm{~h}$ light/dark cycle, and were given ad libitum access to food and water.

Surgical procedures. All surgical procedures were performed under ketamine $(50 \mathrm{mg} / \mathrm{kg}) / \mathrm{xylazine}(2.6 \mathrm{mg} / \mathrm{kg}) /$ acepromazine $(0.5 \mathrm{mg} / \mathrm{kg})$ anesthesia. Chronic intraseptal NGF infusions were made by implanting a cannula within the septum (rostrocaudal, $+0.3 \mathrm{~mm}$; mediolateral, 0.5 $\mathrm{mm}$; dorsoventral, $-6.0 \mathrm{~mm}$ relative to bregma). The cannula was attached to an osmotic pump (Alzet 2002; Alzet) delivering either recombinant human NGF (12 $\mu \mathrm{l} / \mathrm{d}$ of $10 \mu \mathrm{g} / \mathrm{ml}$ solution in vehicle; gift from Genentech) or vehicle [artificial CSF (ACSF) in $0.1 \%$ rat albumin]. The osmotic pump assembly was inserted into a pocket behind the animal's shoulders, enabling the rat to move about in an unrestricted manner. Infusion cannulae remained in place throughout the period of behavioral testing but were removed immediately before starting electrophysiological recordings. The extent of NGF diffusion was assessed immunocytochemically using NGF-specific antibodies (1:1000 dilution) (Conner and Varon, 1996) after subject perfusion with 2\% parafor- 
maldehyde and $0.2 \%$ parabenzoquinone, as previously described (Conner and Varon, 1996).

NGF ELISA. A quantitative assessment of NGF protein levels after intraseptal infusions was made in 12 animals (six NGF and six vehicle). After $7 \mathrm{~d}$ of continuous infusion, animals were killed under deep anesthesia by decapitation, their brains were rapidly removed, and tissues (including medial septum, striatum, parietal cortex, frontal cortex, and hippocampal formation) were dissected on ice and stored at $-80^{\circ} \mathrm{C}$ until assayed in a two-site ELISA specific for NGF (Conner and Varon, 1996).

ChAT assay. The effects of NGF on choline acetyltransferase activity were determined using a quantitative radioenzymatic assay (Fonnum, 1975). In brief, after infusions of NGF or vehicle, animals were decapitated and their brains rapidly dissected on ice. Tissue samples, including hippocampus, septum, and striatum, were weighed and stored at $-80^{\circ} \mathrm{C}$. Samples were sonicated in homogenization buffer containing $0.87 \mathrm{~mm}$ EDTA and $0.1 \%$ Triton X-100, pH 7.0, and ChAT activity was measured by the incorporation of $\left[{ }^{14} \mathrm{C}\right]$ acetyl-coenzyme A into $\left[{ }^{14} \mathrm{C}\right] \mathrm{ACh}$. The protein content of each sample was determined by Bradford protein assay (Bio-Rad), and final activity was expressed in nanomolar ACh $\cdot$ hour $^{-1} \cdot$ milligram protein $^{-1}$.

Morphological assay. The effects of NGF on cholinergic neuron cell size were determined in six NGF-infused $(0.01 \mathrm{mg} / \mathrm{ml}$ for $7 \mathrm{~d})$ and five vehicle-infused animals using stereological procedures. Sections spaced $240 \mu \mathrm{m}$ apart (40 $\mu \mathrm{m}$ thick) were processed for ChAT immunohistochemistry using a polyclonal antibody (Millipore Bioscience Research Reagents; AB144 at 1:500 dilution). A nucleator stereological procedure contained within the Stereo Investigator software (MicroBrightField) was used to determine the mean cross-sectional area for labeled cells. Findings among groups were compared using Student's one-tailed $t$ test with a significance level of $95 \%$.

Selective cholinergic lesions. Lesions of the basal forebrain cholinergic system were made using the IgG-192 immunotoxin (MAB390; Millipore Bioscience Research Reagents), which selectively binds and kills basal forebrain cholinergic cells via the p75 cell surface receptor by disrupting ribosomal function (Wiley et al., 1991; Book et al., 1994). The immonotoxin was administered to 11 rats through a $40 \mu \mathrm{m}$ glass pipette bilaterally at two rostrocaudal locations within the medial septum (rostrocaudal, $+0.4 \mathrm{~mm}$ and 0.0 from bregma). At each site, $0.5 \mu \mathrm{l}$ of the immunotoxin $(0.1 \mathrm{mg} / \mathrm{ml}$ in ACSF $)$ was injected using a Picospritzer (General Valve). Two additional animals received similar injections of ACSF as a control.

Electrophysiology. For electrophysiological recordings, rats were anesthetized with urethane $(1.65 \mathrm{~g} / \mathrm{kg}$, i.p.; Sigma-Aldrich) and placed in a stereotaxic frame. Rectal temperature was maintained at $37 \pm 1^{\circ} \mathrm{C}$. An insulated 70-mm-diameter stainless-steel electrode (A-M Systems) was placed in the dorsal limb of the dentate gyrus $3.3 \mathrm{~mm}$ posterior and 1.2 $\mathrm{mm}$ lateral to bregma. A monopolar stimulating electrode was placed in the ipsilateral perforant path, $3.0 \mathrm{~mm}$ lateral to lambda. Once both electrodes were lowered to elicit optimal recordings, the minimum stimulating current necessary to give a maximal response $\left(S_{\max }\right)$ was determined and baseline EPSPs were elicited by stimulating once every $15 \mathrm{~s}$ with a 0.1 ms pulse of $1 / 3 S_{\max }$ (typically $150-250 \mu \mathrm{A}$ ). The initial slope of the recorded EPSP for each response was measured and averaged across 5 min epochs. A stable $30 \mathrm{~min}$ baseline was recorded before long-term potentiation (LTP) was induced with eight trains of 50 pulses at $100 \mathrm{~Hz}$, $30 \mathrm{~s}$ apart, and posttetanus EPSPs were then recorded for $90 \mathrm{~min}$. Data were acquired and analyzed using LabView 5.1 (National Instruments) on custom written software. All data are given as the percentage change from baseline (mean $\pm \mathrm{SE}$ ) and unpaired $t$ tests were performed using each $5 \mathrm{~min}$ average from all animals in each group as single data points. Immediately after recording, animals were perfused with $4 \%$ paraformaldehyde and their brains were removed for histological verification of cannula and electrode placement (see example in Fig. 3D) using a series of thionin-stained sections spaced $240 \mu \mathrm{m}$ apart.

Behavioral assay. To examine the effects of blocking endogenous NGF on learning and memory, animals received bilateral infusions of a function blocking NGF antibody (Conner and Varon, 1996) or nonspecific rabbit IgG into the dorsal hippocampus. The NGF antibody used in this study completely and specifically inhibits NGF biological activity and does not affect the function or survival of neuronal populations responsive to brain-derived neurotrophic factor (BDNF) or NT-3 (Conner and Varon, 1996). NGF antibody was continuously infused at a concentration of $25 \mathrm{ng} / \mu \mathrm{l} \times 6 \mu \mathrm{l} / \mathrm{d}$ per side, for 1 week before initiating either electrophysiology or behavioral analyses. Previous studies have demonstrated that in vivo infusion of NGF antibodies for 1 week significantly reduces ChAT activity in the septal nucleus (Nitta et al., 1993; Van der Zee et al., 1995). Rats began acquisition testing in the Morris water maze (Morris, 1984) $7 \mathrm{~d}$ after implantation of chronic infusion pumps (Alzet 2002). In brief, 12 rats underwent $10 \mathrm{~d}$ of acquisition testing (two trials per day, $90 \mathrm{~s}$ maximum) in which they were required to learn the location of a hidden platform in a circular fiberglass pool $(152 \mathrm{~cm}$ in diameter). The platform had a constant location in the center of the southwest quadrant of the pool. The rat was lowered into the pool, facing the tank wall, at one of four possible start locations spaced equally around the tank. The choice of start locations was determined pseudorandomly so that on each day the rat was forced to swim one long and one short trial, based on whether the start location was adjacent or opposite to the platform location. For each trial, the swim distance and latency to reach the hidden platform were determined using a video tracking device with Chromotrack software (San Diego Instruments). On each day, motor activity was measured as a function of swim speed (swim distance/latency to reach the platform). Ten days after completion of acquisition trials, rats underwent two additional trials of hidden platform testing to measure retention for platform location. At the completion of testing, animals were perfused with $2 \%$ paraformaldehyde and $0.2 \%$ parabenzoquinone, and brains were sectioned at on a sliding microtome set at $40 \mu \mathrm{m}$. Cannula placement and diffusion of NGF antibody and control IgG (rabbit IgG antibody; Vector Laboratories) were verified histologically.

\section{Results}

\section{NGF augmentation stimulates cholinergic neuronal phenotype and facilitates induction of LTP}

Targeting the cholinergic projection to the hippocampus, we first determined the effects of protracted elevations of relatively low doses of NGF on cell morphology and hippocampal plasticity. Adult Fischer 344 rats received direct intraseptal infusions of NGF at a dose of $0.12 \mu \mathrm{g} / \mathrm{d}$, an amount 10- to 10,000-fold lower than in previous studies that used pharmacological NGF doses (Hefti, 1986; Williams et al., 1986; Koliatsos et al., 1990; Tuszynski et al., 1990; Garofalo et al., 1992; Markowska et al., 1994; Bergado et al., 1997; Kelly et al., 1998), thereby reliably restricting NGF action to septal cholinergic neurons projecting to the hippocampus (Fig. 1). Only cholinergic cell bodies in this region express the receptors trkA and p75 to mediate NGF signal transduction (Sobreviela et al., 1994), thereby limiting NGF effects to cholinergic neurons. Control subjects received vehicle infusions for the same period. After 1 week, ELISA confirmed that NGF levels were significantly elevated only within the septal region $(p=0.020)$ (Fig. 2A), without spread to the hippocampus. Moreover, lowdose NGF infusions within the septum significantly increase choline acetyltransferase activity, determined by RIA, both within septum (mean $\pm \mathrm{SEM}$, vehicle, $96.4 \pm 3.4 \mathrm{nM} \mathrm{ACh} \cdot \mathrm{h}^{-1} \cdot \mathrm{mg}^{-1}$; $\mathrm{NGF}, 165.8 \pm 7.4 \mathrm{nM} \mathrm{ACh} \cdot \mathrm{h}^{-1} \cdot \mathrm{mg}^{-1} ; p<0.0001$, unpaired $t$ test) and within its hippocampal innervation target (vehicle, $53.8 \pm 3.2 \mathrm{nM} \mathrm{ACh} \cdot \mathrm{h}^{-1} \cdot \mathrm{mg}^{-1} ; \mathrm{NGF}, 62.0 \pm 3.4 \mathrm{nM}$ $\mathrm{ACh} \cdot \mathrm{h}^{-1} \cdot \mathrm{mg}^{-1} ; \mathrm{p}<0.05$, unpaired $t$ test). Moreover, NGF delivery within the septum induced significant cholinergic somal hypertrophy of septal cholinergic neurons relative to vehicleinfused subjects ( $p=0.0002$, unpaired $t$ test) (Fig. $2 B$; supplemental Fig. 1, available at www.jneurosci.org as supplemental material). To confirm that NGF effects were restricted to the septum, we also analyzed NGF levels and cell hypertrophy within the adjacent striatum. Previous studies indicate that striatal cholinergic interneurons express the high-affinity trkA receptor 


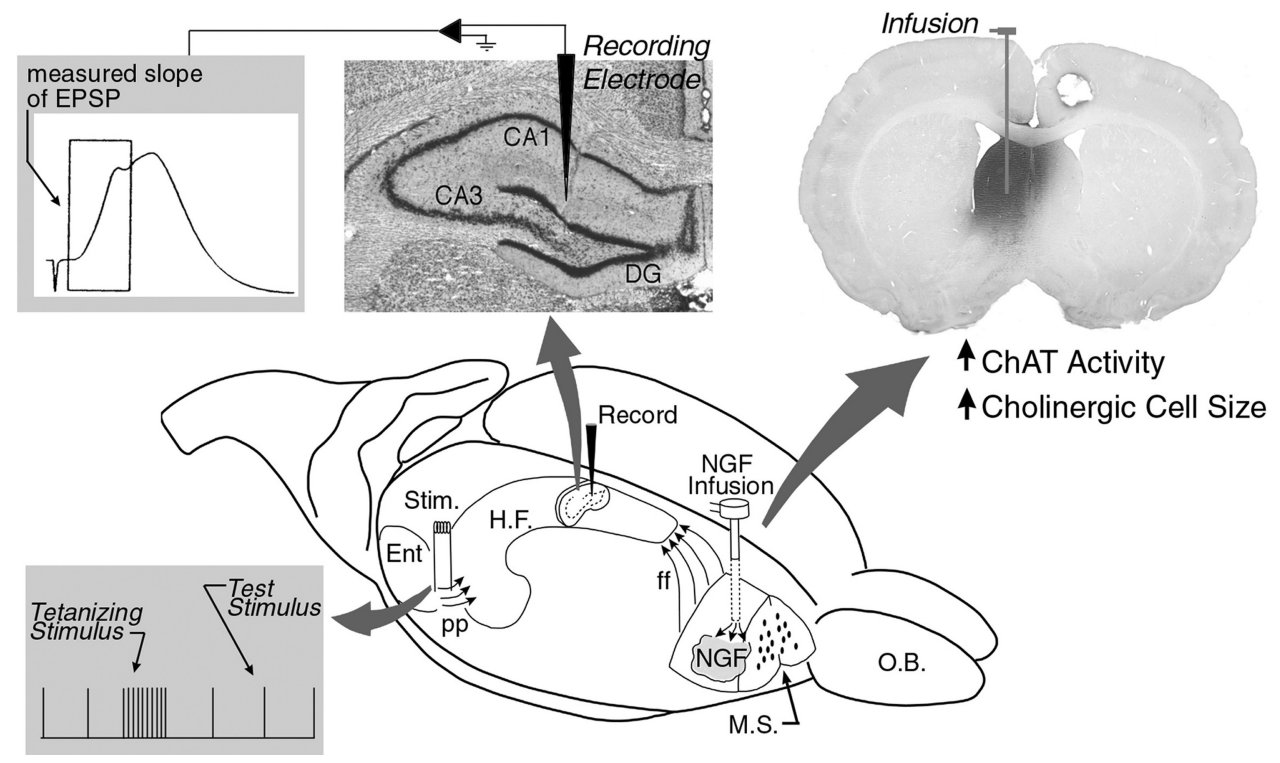

Figure 1. Experimental paradigm for evaluating the effects of modulating septohippocampal cholinergic function with NGF on hippocampal synaptic transmission. Infusing NGF directly within the septal parenchyma restricted actions of NGF to the septal region. Immunohistochemical staining for NGF (top right photograph) demonstrated that NGF delivery was restricted to septal targets, a result confirmed on ELISA (see text). Intraseptal NGF infusions increased cholinergic performance as measured by hypertrophy of cholinergic somata and increased ChAT activity within the septum and hippocampal targets (Fig. 2). The consequences of selectively stimulating septohippocampal cholinergic function on hippocampal synaptic transmission were evaluated in vivo within the entorhinal- dentate pathway. A baseline stimulus was initially applied to the perforant path (pp), and extracellular postsynaptic responses were measured within the dentate gyrus (DG) (top center). After a tetanizing stimulus, responses to intermittent test stimuli were monitored for an additional $90 \mathrm{~min}$, and LTP was expressed as the percentage change in the slope of the initial EPSP (top left trace). This experimental paradigm isolated the three components of the test procedure: stimulation of the synaptic pathway at the level of the perforant path, recording postsynaptic responses within the rostral hippocampal formation (H.F.), and modulating septohippocampal cholinergic transmission remotely within the medial septum (M.S.). Ent, Entorhinal cortex; ff, fimbria fornix; 0.B., olfactory bulb; Stim., stimulating electrode.
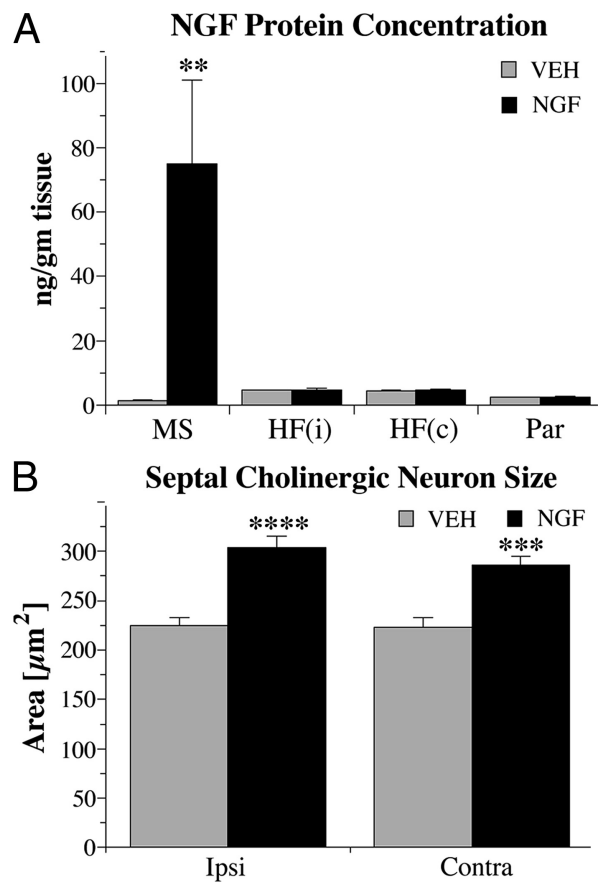

Figure 2. Restricted modulation of the septohippocampal cholinergic system with NGF. $A$, Direct intraseptal infusions elevated NGF levels within the medial septum (MS) $>50$ fold but did not alter NGF levels within the hippocampal formation either ipsilateral $[H F(i)]$ or contralateral $[H F(c)]$ to the infusion $(p>0.4$, unpaired $t$ test), or within overlying parietal cortex (Par) ( $p>0.8$, unpaired $t$ test). $\boldsymbol{B}$, Localized intraseptal NGF infusions modulated septohippocampal cholinergic function, as measured by increases in septal cholinergic cell size, both ipsilateral (Ipsi) and contralateral (Contra) to the infusion site. ${ }^{* *} p<0.025 ;{ }^{* *} p<0.005 ;{ }^{* * *} p<0.001$ compared with vehicle-treated controls (unpaired $t$ test). Error bars indicate SEM.
(Holtzman et al., 1992) and respond to NGF, as evidenced by cell hypertrophy (Gage et al., 1989; Vahlsing et al., 1991). Intraseptal infusions of NGF did not significantly elevate striatal NGF levels and did not induce cell hypertrophy in striatal cholinergic cell bodies ( $p=0.13$, unpaired $t$ test), indicating that NGF action was restricted to the targeted septal cholinergic neurons.

Effects of intraseptal NGF infusions on hippocampal electrophysiology were determined by examining induction of LTP in vivo along the perforant path-dentate gyrus projection. This form of synaptic plasticity is dependent on postsynaptic $\mathrm{Ca}^{2+}$ influx and NMDA receptor activation (Malenka and Nicoll, 1993) and is a postulated mechanism underlying learning and memory (Bliss and Collingridge, 1993). Seven days after the start of NGF intraseptal infusion, tetanic stimuli $\left(1 / 3 S_{\text {max }}\right)$ were applied (see Materials and Methods). The mean slope of the EPSP after 90 min exhibited a significant twofold increase $(p=0.03$, unpaired $t$ test $)$ in NGF-infused animals $(18.4+5.8 \% ; n=6)$ compared with vehicle-infused controls $(4.0+1.7 \% ; n=7)$ (Fig. $3 A$ ), indicating that NGF facilitates the induction of hippocampal LTP. When stronger levels of tetanic stimuli $\left(2 / 3 S_{\max }\right)$ were applied in separate animals, NGF-treated rats tended to show greater levels of LTP (NGF, $36.6+7.4 \%, n=10$; vehicles, $27.8+$ $3.0 \%, n=10$ ) (Fig. $3 B$ ), but this effect did not reach significance ( $p=0.29$ ), possibly because the stronger $2 / 3 S_{\max }$ induction protocol approached saturating levels of stimulation. The process of pump implantation itself did not disrupt septohippocampal function, as naive animals exhibited LTP expression comparable with controls after tetanic stimulation $\left(2 / 3 S_{\max }\right): 30.0+1.2 \%$ $(n=6)$. Differences in paired-pulse depression (data not shown) and short-term depression during high-frequency stimulus trains $(10,40$, and $100 \mathrm{~Hz}$ ) (Fig. 3C) were not observed when NGF- and vehicle-treated animals were compared, suggesting 
A

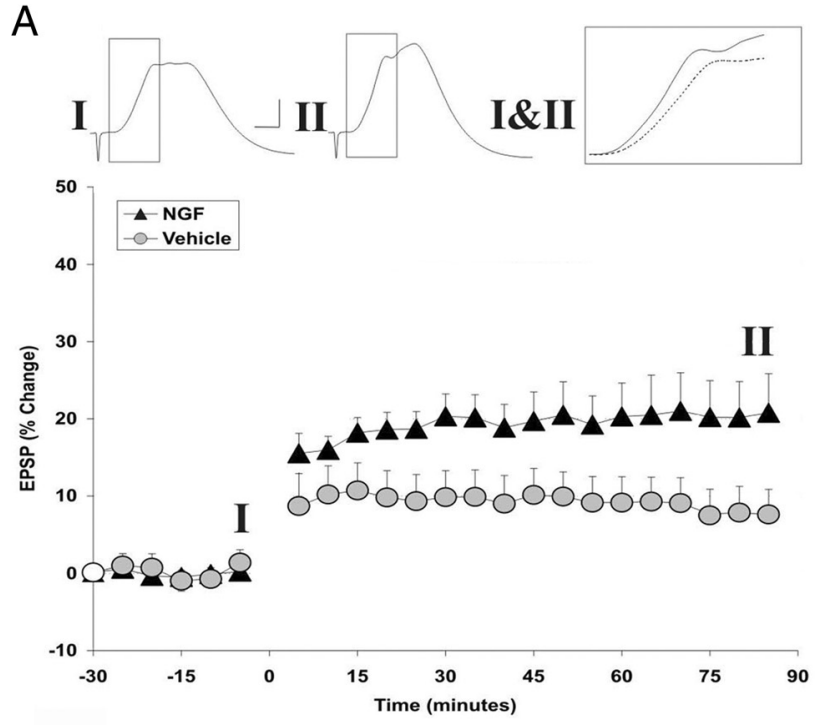

C

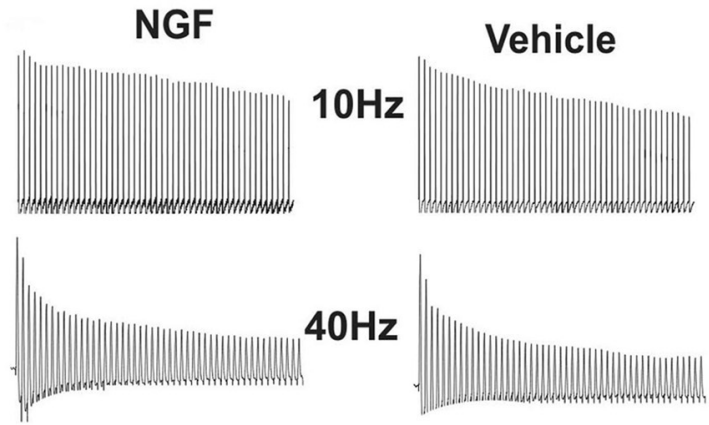

B
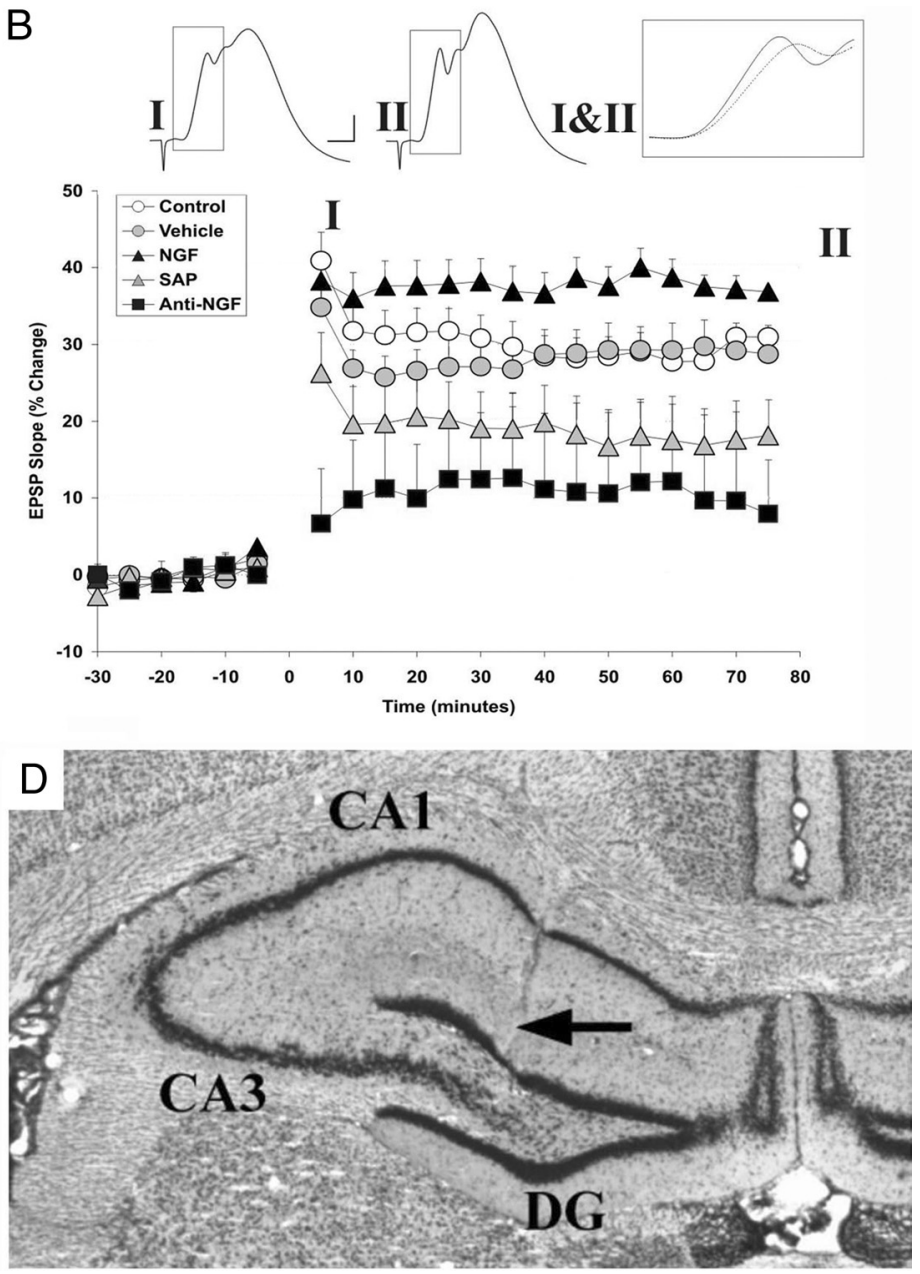

Figure 3. NGF facilitates the induction of hippocampal LTP. A, LTP was induced in NGF- and vehicle-treated animals using a stimulus strength of $1 / 3 S_{\max }$. LTP was measured as the percentage change from baseline in the initial slope of the EPSP. A typical response is shown in inset (NGF treated). Calibration: $2.5 \mathrm{mV}, 2.5 \mathrm{~ms}$. NGF-treated animals showed a significant increase in LTP induction relative to vehicle-treated controls ( $p=0.03$, unpaired $t$ test). $\boldsymbol{B}$, When LTP was induced using a stronger stimulus strength $\left(2 / 3 \mathrm{~S}_{\max }\right)$, NGF-treated animals trended toward higher levels of LTP compared with vehicle-treated and naive controls, although this did not reach significance at these near-saturation levels of $\operatorname{LTP}(p=0.29$, unpaired $t$ test). LTP was significantly reduced in animals with selective depletion of cholinergic inputs to the hippocampus ( $p=0.04$ ) or with specific blockade of NGF signaling ( $p=0.03$ ); no difference between anti-NGF- and SAP-treated animals was observed ( $p=0.3$ ). The inset shows a typical NGF-treated response. Error bars indicate SEM. C, Short-term depression induced by high-frequency stimuli did not differ after NGF stimulation of cholinergic function, suggesting that the mechanism of NGF-induced facilitation of LTP is postsynaptic rather than presynaptic. Stimuli at 10,40, and $100 \mathrm{~Hz}$ were used (only 10 and $40 \mathrm{~Hz}$ are shown in the figure). $\boldsymbol{D}$, Typical electrode penetration site within the dorsal aspect of the dentate gyrus (DG).

that the mechanism of NGF-induced facilitation of LTP is postsynaptic rather than presynaptic. By restricting NGF delivery to the septal nucleus, without direct spread to the hippocampus, it can be concluded that the effects of NGF on LTP were generated via cholinergic inputs, since only cholinergic neurons express trkA receptors that mediate NGF actions. To confirm that cholinergic inputs to hippocampus are targets of NGF actions that could influence LTP, additional subjects received ablative lesions of cholinergic neurons using the selective immunotoxin IgG192-saporin (SAP) (Heckers et al., 1994; Conner et al., 2003): LTP was significantly reduced relative to nonlesioned controls $(18.3+4.5 \% ; p=0.04 ; n=11)($ Fig. $3 B)$. Anatomical analysis in SAP-lesioned animals revealed virtually complete elimination of cholinergic neurons within the medial septum and extensive loss of cholinergic terminals within the hippocampus (Fig. 4).

\section{NGF blockade inhibits LTP and impairs spatial memory}

To test whether NGF is of functional significance in the intact brain, we blocked endogenous NGF in the hippocampus and examined subsequent effects on hippocampal electrophysiology and spatial learning. Rats underwent bilateral intrahippocampal infusions of either function-blocking NGF antibodies (Conner and Varon, 1996) at a concentration of $150 \mathrm{ng} / \mathrm{d}$ per side $(n=$ $10)$, or control rabbit IgG at the same concentration $(n=6)$. The NGF antibody is specific for NGF and does not block the biological activity of either BDNF or NT-3 (Conner and Varon, 1996). Seven days after the start of infusions, LTP induction was examined in vivo after application of tetanic stimuli $\left(2 / 3 S_{\max }\right)$ to the perforant path. NGF antibody-infused subjects exhibited a significant threefold reduction in LTP induction $(8.0+10.4 \%)$ compared with animals infused with a control IgG $(27.9+3.0 \% ; p=0.02)$ or intact animals $(30.0+1.2 \% ; p=0.03)$ (Fig. $3 B, C)$. Levels of LTP induced in anti-NGF treated animals were similar to those observed in SAPlesioned animals $(18.3 \%+4.5 \%$; $p=0.3$, unpaired $t$ test $)$. Thus, blockade of NGF activity in vivo significantly impairs LTP.

To assess the role of endogenous NGF signaling in hippocampalmediated spatial learning, rats received continuous bilateral infusions of either NGF blocking antibodies (150 ng/d per side; $n=12$ ) or the same concentration of a control antibody (rabbit IgG; $n=12$ ) into the dorsal hippocampus. Six intact (nonoperated) animals 

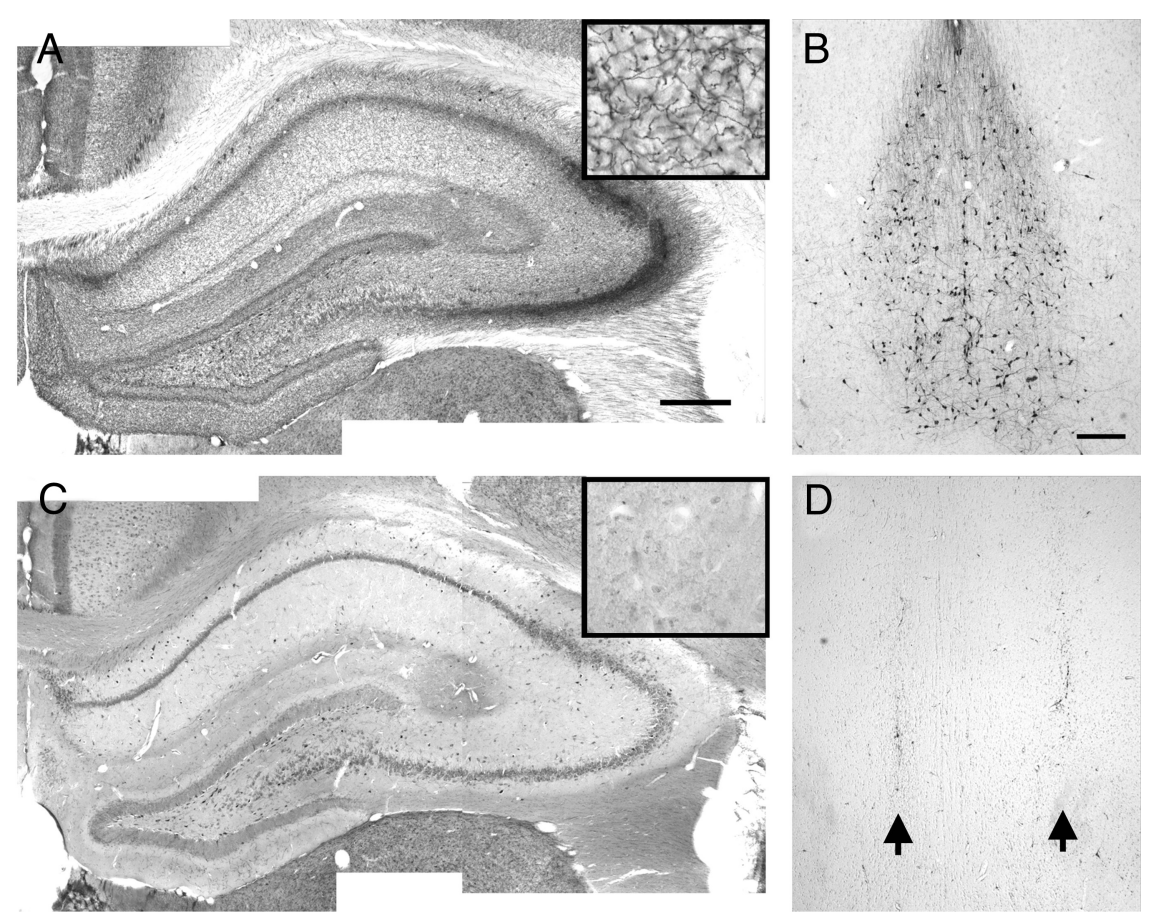

Figure 4. Infusion of the cholinergic-specific neurotoxin IgG-192-SAP depletes the hippocampus of cholinergic innervation. $\boldsymbol{A}, \boldsymbol{B}$, After infusion of vehicle into the septum, a normal pattern of AChE-positive fibers is observed within the hippocampus $(\boldsymbol{A})$, and ChAT-immunoreactive neurons within the medial septum are unaffected (B). C, D, Bilateral injection of 192-lgG-saporotoxin significantly depletes the hippocampus of cholinergic innervation $(\boldsymbol{C})$ and eliminates cholinergic cell bodies in the medial septum (D). The insets in $\boldsymbol{A}$ and $\mathbf{C}$ from stratum radiatum of hippocampus are at higher magnification. The arrows in $\boldsymbol{D}$ indicate needle tracts for injections. Scale bars: $A, 400 \mu \mathrm{m} ; \boldsymbol{B}, 250 \mu \mathrm{m}$.

were also tested. Beginning $7 \mathrm{~d}$ after the start of antibody infusions, spatial learning and memory were assessed in the Morris water maze. Subjects underwent 10 consecutive days of testing (two trials per day, $90 \mathrm{~s}$ maximum), followed by a probe trial on the last day of acquisition. Ten days after completion of acquisition trials, retention of spatial memory was tested in two additional hidden platform sessions. Notably, anti-NGFinfused animals exhibited significant deficits in retention of the platform location relative to IgG-infused controls, both in terms of latency ( $56 \%$ worse, $p=0.05$, unpaired $t$ test; vehicle, $7.8 \pm 0.5 \mathrm{~s}$; anti-NGF, $12.4 \pm 2.2 \mathrm{~s}$ ) and overall swim distance (82\% worse; $p=0.05$, unpaired $t$ test; vehicle, $236.1 \pm 16.1 \mathrm{~cm}$; anti-NGF, $415.6 \pm 86.6 \mathrm{~cm})$. Initial rates of learning did not differ between groups (supplemental Fig. 2, available at www.jneurosci.org as supplemental material). Swim speed ( $p=0.9$, unpaired $t$ test), distance ( $p=0.6$, unpaired $t$ test), and latency ( $p=0.4$, unpaired $t$ test) to reach a visible platform did not differ among groups, indicating that general motor skills or visual acuity were not affected by anti-NGF infusion. Histological examination of brains confirmed appropriate cannula placement and diffusion of antibodies within the hippocampus.

\section{Discussion}

The present findings provide the first direct demonstration that NGF availability can influence hippocampal physiology and behavior in the intact, adult brain by modulating brain cholinergic systems. Selective augmentation of septohippocampal function with NGF significantly facilitates hippocampal plasticity, whereas NGF blockade impairs hippocampal plasticity. Furthermore, NGF blockade significantly impairs memory retention.

The experimental paradigm used in the present study was designed to ensure that NGF actions were mediated by effects on cholinergic projections to the hippocampus. NGF delivery in the augmentation studies was restricted to only cholinergic somata of the septum, confirmed immunocytochemically and by ELISA. These low doses of NGF enhanced the cellular phenotype of septal cholinergic neurons, reflected by somal hypertrophy, and elevated choline acetyltransferase levels both within the septum and remotely in the hippocampus. Importantly, only cholinergic neurons of the basal forebrain express the requisite trkA receptors to mediate responses to NGF (Sobreviela et al., 1994); thus, NGF infusions could not influence other neuronal systems modulating hippocampal activity. In addition, the manner in which NGF modulated hippocampal LTP was consistent with previous reports of cholinergic influences on LTP in the hippocampus and the neocortex: cholinergic antagonists reduce LTP induction in the hippocampus via actions at $\mathrm{M}_{1}$ or $\mathrm{M}_{2}$ muscarinic receptors (Hirotsu et al., 1989; Ovsepian et al., 2004; Luo et al., 2008), whereas cholinergic activation facilitates hippocampal LTP (Blitzer et al., 1990; Burgard and Sarvey, 1990; Bröcher et al., 1992; Segal and Auerbach, 1997) through modulation of hippocampal theta (Pavlides et al., 1988; Huerta and Lisman, 1993; Hasselmo and Barkai, 1995; Hyman et al., 2003). The present study isolates the actions of NGF to ascending cholinergic systems and demonstrates that such actions can influence hippocampal function.

The ability of ascending cholinergic activity to modulate synaptic plasticity has been demonstrated in many brain systems, including the hippocampus and cortex (Bröcher et al., 1992; Huerta and Lisman, 1993; Auerbach and Segal, 1994; Hasselmo and Barkai, 1995). The hypothesis tested in the present study was that trophic factor control of cholinergic function could significantly impact these plastic events. There are several candidate mechanisms whereby NGF may influence cholinergic activity, and thereby induction of LTP. NGF binding to trk-A directly activates the cholinergic gene locus (Berse et al., 1999), inducing somal hypertrophy, choline acetyltransferase enzyme activity, stimulus-evoked release of acetylcholine in target regions (Rylett et al., 1993; Scali et al., 1994), increases in vesicular acetylcholine transporter (Berse et al., 1999), and enhanced high-affinity choline uptake (Williams and Rylett, 1990; Rylett et al., 1993; Berse et al., 1999). Thus, regulating NGF availability may serve as a mechanism for modulating cholinergic tone within innervation targets, and thereby influencing synaptic events. Results from this study are consistent with this proposed hypothesis. An increase in NGF availability stimulates septal cholinergic cell function and facilitates the induction of hippocampal plasticity; reducing NGF availability suppresses cholinergic cell function (Sofroniew et al., 1990) and impairs the induction of hippocampal LTP. The present results provide experimental evidence supporting the notion that trophic factor control of neuromodulatory function can serve as a means of regulating plastic processes in the brain.

The nature of an NGF-induced enhancement of LTP via modulation of cholinergic function is in marked contrast to the man- 
ner in which BDNF has been reported to influence LTP. Early studies indicated that BDNF influences the induction of LTP by acting directly on the excitatory circuits undergoing plasticity, inducing LTP in hippocampus in the absence of tetanizing stimuli (Kang and Shuman, 1995; Messaoudi et al., 1998). However, more recent studies suggest that BDNF transforms early-phase LTP into late-phase LTP, presumably by generating sustained structural and functional changes at potentiated synapses (Lu et al., 2008; Lynch et al., 2008). In contrast to BDNF, NGF exerts a modulatory role in the regulation of hippocampal plasticity but does not independently elicit LTP. Furthermore, whereas BDNF acts acutely and locally on synapses within the hippocampus, NGF is retrogradely transported from the hippocampus to cholinergic somata in the basal forebrain (Schwab et al., 1979); on arrival in the cell soma, NGF stimulates transcriptional events (Huang and Reichardt, 2003) resulting in a more temporally protracted enhancement of the cholinergic phenotype. It is postulated that regulating NGF availability may serve as a mechanism for modulating cholinergic tone within innervation targets. Moreover, NGF systems in the brain may be adapted to regulate the strength of cholinergic activity within innervation targets over more extended time periods, in contrast to BDNF actions that are local, acute, and direct. This hypothesis is supported by the observation that NGF blockade impairs consolidation rather than acquisition of spatial reference memory in the water maze, a mnemonic process that occurs on a time frame of days to weeks (Squire and Alvarez, 1995; Dudai, 2004).

In the present study, NGF was required for consolidation of spatial memory, as evidenced by data indicating that infusions of blocking antibodies impaired recall for the hidden platform location $10 \mathrm{~d}$ after completion of initial acquisition trials in the water maze. This finding is consistent with a previous study that reported hippocampal injection of NGF antisense mRNA impaired retention of platform location (Woolf et al., 2001). The behavioral consequences of blocking NGF action in the intact brain are consistent with the effects of inhibiting cholinergic mechanisms (Fischer et al., 1987; Markowska et al., 1994; Chen and Gage, 1995; Tuszynski and Gage, 1995), further supporting the hypothesis that NGF availability acts as a modulator of cholinergic systems in the intact brain. Interestingly, previous studies investigating the effects of delivering NGF to young, intact adult animals actually demonstrated impaired performance in the Morris water maze (Markowska et al., 1994; Chen and Gage, 1995; Bäckman et al., 1996). These deleterious effects of NGF in previous studies may result from broad spread of NGF within the CNS that elicits side effects of nontargeted delivery (Holtzman et al., 1995) such as pain, or from the high doses of NGF used previously. It is also possible that NGF control of cholinergic function is precisely regulated, with negative consequences resulting from either excessive or insufficient NGF availability.

In conclusion, we find distinct modulatory effects of NGF in the intact adult brain that influence cholinergic neuronal morphology, hippocampal plasticity, and behavior. We postulate that the physiological function of NGF is to modulate the strength of cholinergic projections to hippocampal and cortical targets, thereby modulating neuronal plasticity and, ultimately, behavior.

\section{References}

Auerbach JM, Segal M (1994) A novel cholinergic induction of long-term potentiation in the rat hippocampus. J Neurophysiol 72:2034-2040.

Bäckman C, Rose GM, Hoffer BJ, Henry MA, Bartus RT, Friden P, Granholm AC (1996) Systemic administration of a nerve growth factor conjugate reverses age-related cognitive dysfunction and prevents cholinergic neuron atrophy. J Neurosci 16:5437-5442.

Bergado JA, Fernández CI, Gómez-Soria A, González O (1997) Chronic intraventricular infusion with NGF improves in old cognitively-impaired rats. Brain Res 770:1-9.

Berse B, Lopez-Coviella I, Blusztajn JK (1999) Activation of TrkA by nerve growth factor upregulates expression of the cholinergic gene locus but attenuates the response to ciliary neurotrophic growth factor. Biochem J 342:301-308.

Bliss TV, Collingridge GL (1993) A synaptic model of memory: long-term potentiation in the hippocampus. Nature 361:31-39.

Blitzer RD, Gil O, Landau EM (1990) Cholinergic stimulation enhances long-term potentiation in the CA1 region of the rat hippocampus. Neurosci Lett 119:207-210.

Book AA, Wiley RG, Schweitzer JB (1994) 192 IgG-saporin: I. Specific lethality for cholinergic neurons in the basal forebrain of the rat. J Neuropathol Exp Neurol 53:95-102.

Bröcher S, Artola A, Singer W (1992) Agonists of cholinergic and noradrenergic receptors facilitate synergistically the induction of long-term potentiation in slices of rat visual cortex. Brain Res 573:27-36.

Brooks AI, Cory-Slechta DA, Federoff HJ (2000) Gene-experience interaction alters the cholinergic septohippocampal pathway of mice. Proc Natl Acad Sci U S A 97:13378-13383.

Burgard EC, Sarvey JM (1990) Muscarinic receptor activation facilitates the induction of long-term potentiation (LTP) in the rat dentate gyrus. Neurosci Lett 116:34-39.

Chen KS, Gage FH (1995) Somatic gene transfer of NGF to the aged brain: behavioral and morphological amelioration. J Neurosci 15:2819-2825.

Conner JM, Tuszynski MH (1999) Cholinergic lesions as a model of Alzheimer's disease: effects of nerve growth factor. In: Central nervous system diseases (Emerich DF, Dean RLI, Sanberg PR, eds), pp 65-80. Totowa, NJ: Humana.

Conner JM, Varon S (1992) Distribution of nerve growth factor-like immunoreactive neurons in the adult rat brain following colchicine treatment. J Comp Neurol 326:347-362.

Conner JM, Varon S (1996) Characterization of antibodies to nerve growth factor: assay-dependent variability in the cross-reactivity with other neurotrophins. J Neurosci Methods 65:93-99.

Conner JM, Culberson A, Packowski C, Chiba AA, Tuszynski MH (2003) Lesions of the basal forebrain cholinergic system impair task acquisition and abolish cortical plasticity associated with motor skill learning. Neuron 38:819-829.

Dudai Y (2004) The neurobiology of consolidations, or, how stable is the engram? Annu Rev Psychol 55:51-86.

Fischer W, Wictorin K, Björklund A, Williams LR, Varon S, Gage FH (1987) Amelioration of cholinergic neuron atrophy and spatial memory impairment in aged rats by nerve growth factor. Nature 329:65-68.

Fonnum F (1975) A rapid radiochemical method for the determination of choline acetyltransferase. J Neurochem 24:407-409.

Gage FH, Batchelor P, Chen KS, Chin D, Higgins GA, Koh S, Deputy S, Rosenberg MB, Fischer W, Bjorklund A (1989) NGF receptor reexpression and NGF-mediated cholinergic neuronal hypertrophy in the damaged adult neostriatum. Neuron 2:1177-1184.

Garofalo L, Ribeiro-da-Silva A, Cuello AC (1992) Nerve growth factorinduced synaptogenesis and hypertrophy of cortical cholinergic terminals. Proc Natl Acad Sci U S A 89:2639-2643.

Hasselmo ME, Barkai E (1995) Cholinergic modulation of activity-dependent synaptic plasticity in the piriform cortex and associative memory function in a network biophysical simulation. J Neurosci 15:6592-6604.

Heckers S, Ohtake T, Wiley RG, Lappi DA, Geula C, Mesulam MM (1994) Complete and selective cholinergic denervation of rat neocortex and hippocampus but not amygdala by an immunotoxin against the p75 NGF receptor. J Neurosci 14:1271-1289.

Hefti F (1986) Nerve growth factor promotes survival of septal cholinergic neurons after fimbrial transections. J Neurosci 6:2155-2162.

Hirotsu I, Hori N, Katsuda N, Ishihara T (1989) Effect of anticholinergic drug on long-term potentiation in rat hippocampal slices. Brain Res 482:194-197.

Holtzman DM, Li Y, Parada LF, Kinsman S, Chen C-K, Valletta JS, Zhou J, Long JB, Mobley WC (1992) p140trk mRNA marks NGF-responsive forebrain neurons: evidence that trk gene expression is induced by NGF. Neuron 9:465-478. 
Holtzman DM, Kilbridge J, Li Y, Cunningham ET Jr, Lenn NJ, Clary DO, Reichardt LF, Mobley WC (1995) TrkA expression in the CNS: evidence for the existence of several novel NGF-responsive CNS neurons. J Neurosci 15:1567-1576.

Huang EJ, Reichardt LF (2003) Trk receptors: roles in neuronal signal transduction. Annu Rev Biochem 72:609-642.

Huerta PT, Lisman JE (1993) Heightened synaptic plasticity of hippocampal CA1 neurons during a cholinergically induced rhythmic state. Nature 364:723-725.

Hyman JM, Wyble BP, Goyal V, Rossi CA, Hasselmo ME (2003) Stimulation in hippocampal region CA1 in behaving rats yields long-term potentiation when delivered to the peak of theta and long-term depression when delivered to the trough. J Neurosci 23:11725-11731.

Kang H, Schuman EM (1995) Long-lasting neurotrophin-induced enhancement of synaptic transmission in the adult hippocampus. Science 267:1658-1662.

Kelly A, Conroy S, Lynch MA (1998) Evidence that nerve growth factor plays a role in long-term potentiation in the rat dentate gyrus. Neuropharmacology 37:561-570.

Koliatsos VE, Nauta HJ, Clatterbuck RE, Holtzman DM, Mobley WC, Price DL (1990) Mouse nerve growth factor prevents degeneration of axotomized basal forebrain cholinergic neurons in the monkey. J Neurosci 10:3801-3813.

Large TH, Bodary SC, Clegg DO, Weskamp G, Otten U, Reichardt LF (1986) Nerve growth factor gene expression in the developing rat brain. Science 234:352-355.

Lu Y, Christian K, Lu B (2008) BDNF: a key regulator for protein synthesisdependent LTP and long-term memory? Neurobiol Learn Mem 89:312-323.

Luo L, Chen WH, Wang M, Zhu DM, She JQ, Ruan DY (2008) Modulation of long-term potentiation by individual subtypes of muscarinic acetylcholine receptor in the rat dentate gyrus. Hippocampus 18:989-995.

Lynch G, Rex CS, Chen LY, Gall CM (2008) The substrates of memory: defects, treatments, and enhancement. Eur J Pharmacol 585:2-13.

Malenka RC, Nicoll RA (1993) NMDA-receptor-dependent synaptic plasticity: multiple forms and mechanisms. Trends Neurosci 16:521-527.

Markowska AL, Koliatsos VE, Breckler SJ, Price DL, Olton DS (1994) Human nerve growth factor improves spatial memory in aged but not young rats. J Neurosci 14:4815-4824.

Messaoudi E, Bârdsen K, Srebro B, Bramham CR (1998) Acute intrahippocampal infusion of BDNF induces lasting potentiation of synaptic transmission in the rat dentate gyrus. J Neurophysiol 79:496-499.

Morris R (1984) Developments of a water-maze procedure for studying spatial learning in the rat. J Neurosci Methods 11:47-60.

Nitta A, Murase K, Furukawa Y, Hayashi K, Hasegawa T, Nabeshima T (1993) Memory impairment and neural dysfunction after continuous infusion of anti-nerve growth factor antibody into the septum in adult rats. Neuroscience 57:495-499.

Ovsepian SV, Anwyl R, Rowan MJ (2004) Endogenous acetylcholine lowers the threshold for long-term potentiation induction in the CAl area through muscarinic receptor activation: in vivo study. Eur J Neurosci 20:1267-1275.

Pavlides C, Greenstein YJ, Grudman M, Winson J (1988) Long-term poten- tiation in the dentate gyrus is induced preferentially on the positive phase of theta-rhythm. Brain Res 439:383-387.

Rylett RJ, Goddard S, Schmidt BM, Williams LR (1993) Acetylcholine synthesis and release following continuous intracerebral administration of NGF in adult and aged Fischer-344 rats. J Neurosci 13:3956-3963.

Scali C, Casamenti F, Pazzagli M, Bartolini L, Pepeu G (1994) Nerve growth factor increases extracellular acetylcholine levels in the parietal cortex and hippocampus of aged rats and restores object recognition. Neurosci Lett 170:117-120.

Schwab ME, Otten U, Agid Y, Thoenen H (1979) Nerve growth factor (NGF) in the rat CNS: absence of specific retrograde axonal transport and tyrosine hydroxylase induction in locus coeruleus and substantia nigra. Brain Res 168:473-483.

Segal M, Auerbach JM (1997) Muscarinic receptors involved in hippocampal plasticity. Life Sci 60:1085-1091.

Sobreviela T, Clary DO, Reichardt LF, Brandabur MM, Kordower JH, Mufson EJ (1994) TrkA-immunoreactive profiles in the central nervous system: colocalization with neurons containing $\mathrm{p} 75$ nerve growth factor receptor, choline acetyltransferase, and serotonin. J Comp Neurol 350:587-611.

Sofroniew MV, Galletly NP, Isacson O, Svendsen CN (1990) Survival of adult basal forebrain cholinergic neurons after loss of their target neurons. Science 247:338-342.

Squire LR, Alvarez P (1995) Retrograde amnesia and memory consolidation: a neurobiological perspective. Curr Opin Neurobiol 5:169-177.

Tuszynski MH, Gage FH (1995) Bridging grafts and transient nerve growth factor infusions promote long-term central nervous system rescue and partial functional recovery. Proc Natl Acad Sci U S A 92:4621-4625.

Tuszynski MH, U H-S, Amaral DG, Gage FH (1990) Nerve growth factor infusions in primate brain reduces lesion-induced cholinergic neuronal degeneration. J Neurosci 10:3604-3614.

Vahlsing HL, Hagg T, Spencer M, Conner JM, Manthorpe M, Varon S (1991) Dose-dependent responses to nerve growth factor by adult rat cholinergic medial septum and neostriatum neurons. Brain Res 552:320-329.

Van der Zee CEEM, Lourenssen S, Stanisz J, Diamond J (1995) NGF deprivation of adult rat brain results in cholinergic hypofunction and selective impairments in spatial learning. Eur J Neurosci 7:160-168.

Whittemore SR, Ebendal T, Lärkfors L, Olson L, Seiger A, Strömberg I, Persson H (1986) Developmental and regional expression of beta nerve growth factor messanger RNA and protein in the rat central nervous system. Proc Natl Acad Sci U S A 83:817-821.

Wiley RG, Oeltmann TN, Lappi DA (1991) Immunolesioning: selective destruction of neurons using immunotoxin to rat NGF receptor. Brain Res 562:149-153.

Williams LR, Rylett RJ (1990) Exogenous nerve growth factor increases the activity of high-affinity choline uptake and choline acetyltransferase in brain of Fisher 344 male rats. J Neurochem 55:1042-1049.

Williams LR, Varon S, Peterson GM, Wictorin K, Fischer W, Bjorklund A, Gage FH (1986) Continuous infusion of nerve growth factor prevents forebrain neuronal death after fimbria-fornix transection. Proc Natl Acad Sci U S A 83:9231-9235.

Woolf NJ, Milov AM, Schweitzer ES, Roghani A (2001) Elevation of nerve growth factor and antisense knockdown of TrkA receptor during contextual memory consolidation. J Neurosci 21:1047-1055. 